\title{
Control of periplasmic nitrate reductase gene expression (napEDABC) from Paracoccus pantotrophus in response to oxygen and carbon substrates
}

\author{
Heather J. Sears, ${ }^{1,3}$ Gary Sawers, ${ }^{2}$ Ben C. Berks, ${ }^{1}$ Stuart J. Ferguson ${ }^{3}$ \\ and David J. Richardson ${ }^{1}$
}

Author for correspondence: David J. Richardson. Tel: +44 1603 593250. Fax: +44 1603592250. e-mail: d.richardson@uea.ac.uk

1 Centre for Metalloprotein Spectroscopy and Biology, School of Biological Sciences, University of East Anglia, Norwich Research Park, Norwich NR4 7TJ, UK

2 Department of Molecular Microbiology, John Innes Centre, Norwich Research Park, Norwich, UK

3 Department of Biochemistry, University of Oxford, Oxford, UK

\begin{abstract}
The napEDABC operon of Paracoccus pantotrophus encodes a periplasmic nitrate reductase (NAP), together with electron-transfer components and proteins required for the synthesis of a fully functional enzyme. Previously, it had been shown that high NAP activity was observed when $P$. pantotrophus was grown aerobically on highly reduced carbon sources such as butyrate or caproate, but not when cultured on more oxidized substrates such as succinate or malate. The enzyme is not present to any extent when the organism is grown anaerobically under denitrifying conditions, regardless of the carbon source. Transcriptional analyses of the nap operon have now identified two initiation sites which were differentially regulated in response to the carbon source, with expression being maximal when cells were grown aerobically with butyrate. Analysis of a P. pantotrophus mutant (M6) deregulated for NAP activity identified a single $C \rightarrow A$ transversion in a heptameric inverted-repeat sequence that partially overlapped the proximal promoter. Transcription analysis of this mutant revealed that expression of nap was completely derepressed under all growth conditions examined. Taken together, these findings indicate that nap transcription is negatively regulated during anaerobiosis, such that expression is restricted to aerobic growth, but only when the carbon source is highly reduced.
\end{abstract}

Keywords: Periplasmic nitrate reductase, oxygen regulation, transcription, repression, Paracoccus

\section{INTRODUCTION}

The denitrifying bacterium Paracoccus pantotrophus (f. sp. Thiosphaera pantotropha) has three types of nitrate reductase (Sears et al., 1997). A membrane-bound respiratory nitrate reductase (NAR) is synthesized during anaerobic growth, a periplasmic respiratory nitrate reductase (NAP) is synthesized during aerobic growth and a cytoplasmic assimilatory nitrate reductase is synthesized in the absence of ammonium (Bell et al., 1990, 1993; Sears et al., 1997). Electron transport from $\mathrm{UQH}_{2}$ to nitrate via NAR is electrogenic, whereas electron transport from $\mathrm{UQH}_{2}$ to nitrate via NAP is likely to be non-electrogenic so that the free energy in

Abbreviations: $\mathrm{MV}^{+}$, reduced methyl viologen; NAP, periplasmic nitrate reductase; NAR, membrane-bound nitrate reductase. the $\mathrm{UQH}_{2} /$ nitrate redox couple is dissipated (Berks et al., 1995). Under heterotrophic growth conditions, $\mathrm{NADH}$ is the major electron donor to the UQ pool. This allows respiratory electron transfer to NAP to be coupled to the generation of proton-motive force at the level of the proton-translocating NADH dehydrogenase. Nevertheless, nitrate respiration during aerobic growth $\left(\mathrm{q}^{+} / 2 \mathrm{e}^{-}=4\right.$, where $\mathrm{q}$ is the charge translocated) will be less highly coupled than oxygen respiration via the cytochrome $a a_{3}$ oxidase $\left(\mathrm{q}^{+} / 2 \mathrm{e}^{-}=10\right)$. As a consequence, the role of aerobic nitrate respiration may be to provide a poorly coupled route for oxidation of excess reducing equivalents to maintain the cellular redox balance during oxidative metabolism of highly reduced carbon substrates (Richardson \& Ferguson, 1992; Sears et al., 1997). In support of this proposed role, both the synthesis of NAP and electron flux through the enzyme 
are higher during aerobic growth on highly reduced carbon substrates such as butyrate and caproate, compared to the more oxidized carbon substrates such as malate and succinate (Richardson \& Ferguson, 1992; Sears et al., 1997). It follows, therefore, that the control of NAP synthesis when P. pantrotrophus is cultivated on different carbon substrates may be responsive to the cellular redox state.

NAP is present in a wide range of $\alpha, \beta, \gamma$, and $\delta$ Proteobacteria (Berks et al., 1995). The role of NAP, and consequently the pattern of nap gene expression, varies amongst the systems that have thus far been investigated. In Haemophilus influenzae, NAP is the only nitrate reductase present and the role for NAP presumably is to support anaerobic growth in the presence of nitrate. NAP is also the sole nitrate reductase in the denitrifying bacterium Pseudomonas sp. strain G179. Mutation in the NAP region rendered the cells incapable of growth under anaerobic conditions with nitrate as the electron acceptor, showing that the primary role of NAP in this bacterium is in respiratory nitrate reduction (Bedzyk et al., 1999). Mutation of NAP in Rhodobacter sphaeroides f. sp. denitrificans also clearly demonstrated that it is the only nitrate reductase involved in anaerobic denitrification (Liu et al., 1999).

In Escherichia coli, the situation is more complex since the organism possesses two isozymes of the NAR in addition to NAP. Transcription of the nap genes is induced by anaerobiosis in the presence of nitrate or nitrite (Darwin \& Stewart, 1995). Expression of the nap operon is under the positive control of the transcription factors FNR and NarP; however, it is antagonized by NarL, which binds to the same site as NarP. Recent work has suggested that the NAP system has a high affinity for nitrate in the intact cell, and that the nap genes are transcribed only at low nitrate concentrations (Potter et al., 1999; Wang et al., 1999). This has suggested a role for NAP in anaerobic respiration in nitrate-limited environments.

The denitrifying bacterium Ralstonia eutropha also possesses membrane-bound, periplasmic and assimilatory nitrate reductases and, as in $P$. pantotrophus, synthesis of NAP is confined to aerobic growth conditions (Siddiqui et al., 1993). It is probable that the fundamental principles of NAP regulation will be similar in bacteria that synthesize the enzyme during aerobic growth and an understanding of the molecular basis of this regulation will complement physiological studies on the function of the enzyme. As a first step towards this, the organization and transcriptional regulation of the nap operon in P. pantotrophus has been investigated. Our findings reveal that expression of the nap operon is subject to induction aerobically, but only when the organism is growing on highly reduced carbon substrates, such as butyrate. Remarkably, operon expression is also negatively regulated in response to anaerobiosis. This unusual control of gene expression is intriguing as it may represent regulation exerted at the level of the oxidation state of the carbon source that only occurs in the presence of dioxygen.

\section{METHODS}

Bacterial strains, plasmids and growth conditions. The bacterial strains and plasmids used in this study are listed in Table 1. All strains were grown at $37^{\circ} \mathrm{C}$. E. coli and $P$. pantotrophus strains used for filter matings were grown in Luria-Bertani (LB) medium. Cells for enzyme assays and RNA preparation were grown on the minimal salts medium described by Robertson \& Kuenen (1983) with the appropriate carbon substrate added to a final concentration of $30 \mathrm{mM}$ as described previously (Sears et al., 1993). Cellular fractionation and reduced methy viologen $\left(\mathrm{MV}^{+}\right)$-dependent nitrate reductase activity assays were performed as described previously (Sears et al., 1993).

Antibiotics were added to the following final concentrations: ampicillin, $100 \mu \mathrm{g} \mathrm{ml}^{-1}$; kanamycin, $20 \mu \mathrm{g} \mathrm{ml}^{-1}$ for E. coli or $100 \mu \mathrm{g} \mathrm{ml}^{-1}$ for P. pantotrophus; spectinomycin, $25 \mu \mathrm{g} \mathrm{ml} \mathrm{m}^{-1}$ for E. coli or $50 \mu \mathrm{g} \mathrm{ml}^{-1}$ for P. pantotrophus; streptomycin, $50 \mu \mathrm{g} \mathrm{ml}^{-1}$; chloramphenicol, $25 \mu \mathrm{g} \mathrm{ml}^{-1}$.

Recombinant DNA techniques. Standard methods of recombinant DNA technology were used (Sambrook et al., 1989).

Primer extension analysis. Total RNA was isolated from aerobic and anaerobic cultures grown to mid-exponential phase using the Qiagen RNeasy kits. Primer extension analysis of the specific transcripts generated from promoters P1 and P2 was performed essentially as described by Sawers \& Böck (1989) using $15 \mu \mathrm{g}$ total RNA and $0 \cdot 1 \mathrm{pmol}$ specific ${ }^{32} \mathrm{P}-$ labelled oligonucleotide NapEpx (5'-CGCTTGCGGTGCTTGGGAC-3'), which annealed within the napE gene (Berks et al., 1995). Sequencing reactions were performed according to the procedure of Sanger et al. (1977) using the same labelled primer and plasmid pHJS110.

Construction of HJS101 (napE::Km $\left.{ }^{r}\right)$. The first step in the construction of a P. pantotrophus napE mutant strain involved PCR to generate fragments of napE with suitable restriction sites to facilitate cloning of a kanamycin cassette. The primer pairs hsp86 (5'-TCGTTCCCGGGCCTGTCCACC-3')/hsp87 (5'-TCGCGGATCCGATCATTTCTGG-3') and hsp88 (5'-CGGCGGATCCGGCTTCCTGGT-3')/hsp89 (5'-GGCGCCATGCATCGTCTTGGACA-3') were used to amplify $476 \mathrm{bp}$ and $701 \mathrm{bp}$ fragments, respectively, from cos154. The 476 bp fragment was restricted with $S m a \mathrm{I} / \mathrm{BamHI}$ and ligated into SmaI/BamHI-restricted pUC18 to generate pHJS100. The 710 bp fragment was restricted with BamHI/ $S p h I$ and ligated into BamHI/SphI-restricted pUC18 to generate pHJS101. The SphI-BamHI insert from pHJS101 was cloned into pHJS100 to generate pHJS102, which has a $111 \mathrm{bp}$ in-frame deletion in napE. The deletion is marked by a Bam HI site into which the kanamycin-resistance cassette from pUC4K was cloned to generate $\mathrm{pHJS103.} \mathrm{The} \mathrm{complete} \mathrm{insert}$ was then cloned into pGRPD1 as a SphI-EcoRI fragment to construct pHJS104. This plasmid was mobilized into $P$. pantotrophus in a triparental mating using pRK2013 as a helper plasmid (Figurski \& Helinski, 1979). Kanamycinresistant exconjugants were isolated and the presence of the kanamycin cassette in napE was verified by Southern analysis of genomic DNA. The resulting strain was called HJS101.

Construction of HJS105 (Anap). To construct a strain deleted for the nap operon, plasmid derivatives carrying appropriate DNA fragments from the operon first had to be constructed. Plasmid pHJS200 was constructed by cloning a $1.25 \mathrm{~kb}$ FspI-XbaI fragment from pSPHI into PmlI/XbaI-restricted pSPH22, generating a deletion of the nap operon and flanking DNA from 306 bp upstream of the napE start codon to $217 \mathrm{bp}$ downstream of the napC stop codon. The pHJS200 insert was 
Table 1. Strains and plasmids used in this work

\begin{tabular}{|c|c|c|}
\hline Strain/plasmid & Relevant characteristics & Source/reference \\
\hline \multicolumn{3}{|l|}{ P. pantotrophus strains } \\
\hline GB17 & Wild-type & Robertson \& Kuenen (1983) \\
\hline M6 & narH:: $\operatorname{Tn} 5$ & Bell et al. (1993) \\
\hline $\mathrm{M} 6 \Omega$ & narH::Tn5, nap $A:: \Omega$ & Sears et al. (1997) \\
\hline HJS101 & $n a p E:: \mathrm{Km}^{\mathrm{r}}$ & This work \\
\hline HJS105 & $\triangle n a p E D A B C$ & This work \\
\hline BCB12 & $\operatorname{narl}:: \Omega$ & This work \\
\hline \multicolumn{3}{|l|}{ E. coli strains } \\
\hline $\mathrm{DH} 5 \alpha$ & 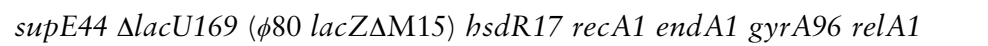 & Hanahan (1983) \\
\hline GM2163 & $\operatorname{dam} 13:: \operatorname{Tn} 9\left(\mathrm{Cm}^{\mathrm{r}}\right) d c m-6$ hsdR2 & New England Biolabs \\
\hline \multicolumn{3}{|l|}{ Plasmids } \\
\hline pUC18 & $A m p^{r}$, general cloning vector & Yanish-Perron et al. (1985) \\
\hline pBluescript II SK $(+)$ & $A m p^{r}$, general cloning vector & Stratagene \\
\hline pET21a $(+)$ & $A_{m p}{ }^{r}$, unique $N d e I$ site & Novagen \\
\hline pUC4K & $\mathrm{Km}^{\mathrm{r}}$ & Vieira \& Messing (1982) \\
\hline $\mathrm{pHP} 45 \Omega$ & $S p^{r} A m p^{r}$ & Prentki \& Krisch (1984) \\
\hline pCR-Script SK $(+)$ & $A m p^{r}$ & Stratagene \\
\hline pGRPD1 & $\mathrm{Amp}^{\mathrm{r}} \mathrm{Sp}^{\mathrm{r}}$, oriV (ColE1) oriT & Van Spanning et al. (1990) \\
\hline pRVS1 & $\mathrm{Amp}^{\mathrm{r}} \mathrm{Sp}^{\mathrm{r}}$, oriV (ColE1) oriT $\operatorname{Tn} 5 p$ lac $\mathrm{Z}$ & Van Spanning et al. (1991) \\
\hline pJB3Km1 & $\mathrm{Km}^{\mathrm{r}} \mathrm{Amp}^{\mathrm{r}}$, oriV $(\operatorname{IncP} \alpha)$ & Blatny et al. (1997) \\
\hline pRK2013 & $\mathrm{Km}^{\mathrm{r}}$, oriV (ColE1) oriT, conjugative helper plasmid & Figurski \& Helinski (1979) \\
\hline $\cos 154$ & $\begin{array}{l}\sim 40 \mathrm{~kb} \text { insert from } P \text {. pantotrophus genome including napEDA' in } \\
\text { Supercos } 1\end{array}$ & Berks et al. (1995) \\
\hline $\cos 295$ & $\begin{array}{l}\sim 40 \mathrm{~kb} \text { insert from } P . \text { pantotrophus genome including nap } p^{\prime} A B C \text { in } \\
\text { Supercos } 1\end{array}$ & Berks et al. (1995) \\
\hline pHJS4 & $4 \cdot 4 \mathrm{~kb} B f a \mathrm{I}$ fragment from $\cos 154$ cloned in NdeI site of pET21a & This work \\
\hline pHJS100 & PCR fragment from $\operatorname{dct} M-n a p E$ in pUC18 & This work \\
\hline pHJS100M6 & PCR fragment from P. pantotrophus M6 dctM-napE in pUC18 & This work \\
\hline pHJS101 & PCR fragment from napE-napA in pUC18 & This work \\
\hline pHJS102 & In-frame deletion in napE cloned into pUC18 & This work \\
\hline pHJS103 & pHJS102 with Km cassette at site of deletion & This work \\
\hline pHJS104 & Insert from pHJS103 transferred into pGRPD1 & This work \\
\hline pSPH1 & $3.5 \mathrm{~kb} S p h \mathrm{I}$ fragment from $\cos 154$ in pUC18 & Berks et al. (1995) \\
\hline pSPH22 & $6.0 \mathrm{~kb}$ SphI fragment from $\cos 154$ in pUC18 & Berks et al. (1995) \\
\hline pHJS200 & $\triangle n a p E D A B C$ in $p U C 18$ & This work \\
\hline pHJS201 & Insert from pHJS200 in pRVS1 & This work \\
\hline pHJS300 & $\begin{array}{l}\text { PCR fragment }-178 \text { to }+85 \text { relative to } \mathrm{P} 1 \text { transcription start in pCR- } \\
\text { Script }\end{array}$ & This work \\
\hline pHJS302 & $\begin{array}{l}\text { napEDABC plus } 178 \text { bp upstream of } \mathrm{P} 1 \text { transcription start in pBluescript } \\
\text { II SK(+) }\end{array}$ & This work \\
\hline pHJS304 & pHJS302 insert in pJB3Km1 & This work \\
\hline pHJS305 & pHJS303 insert in pJB3Km1 & This work \\
\hline pHJS306 & $\begin{array}{l}\text { PCR fragment }-178 \text { to }+85 \text { relative to } \mathrm{P} 1 \text { transcription start from M6 in } \\
\text { pCR-Script }\end{array}$ & This work \\
\hline pHJS307 & $\begin{array}{l}\text { napEDABC plus } 178 \text { bp upstream of } \mathrm{P} 1 \text { transcription start in pBluescript } \\
\text { II SK(+) }\end{array}$ & This work \\
\hline pHJS308 & pHJS306 insert in pJB3Km1 & This work \\
\hline
\end{tabular}

excised with $S m a \mathrm{I} / S p h \mathrm{I}$ and ligated into pRVS1 to generate pHJS201. This plasmid was mobilized into $P$. pantotrophus HJS101 in a triparental mating, and kanamycin- and spectinomycin-resistant exconjugants were selected. One of these colonies was resuspended in $1 \mathrm{ml} \mathrm{LB}$ and serial dilutions were plated onto LB. Resultant colonies were resuspended in LB and serially diluted onto LB plates containing X-Gal at
$80 \mu \mathrm{g} \mathrm{ml}^{-1}$. The white colonies of recombinant cells were plated in duplicate in the absence and presence of kanamycin. Mutant strains, in which the insertionally inactivated gene had been replaced by the one with a deletion showed a kanamycinand spectinomycin-sensitive phenotype. The deletion of $n a p E D A B C$ was verified by Southern analysis and the strain was called HJS105. 
Construction of pHJS304. The primer pairs Hind826N $\left(5^{\prime}-\right.$ GGCGCTTTAAAGCTTCTAGGCCCG-3')/NapEpx were used in PCR to amplify a $263 \mathrm{bp}$ fragment from the napE promoter. The fragment was cloned into pCR-Script to generate pHJS300. Plasmid pHJS302 was made by three-way ligation. The first fragment was the insert of plasmid pHJS300 excised with HindIII/ClaI, the second fragment was the $4.2 \mathrm{~kb}$ ClaI-XhoI fragment from pHJS4 and the third fragment was derived from pBluescript II SK $(+)$ by digestion with HindIII/ XhoI. The pHJS302 insert was excised with SacI and ligated into SacI-restricted pJB3Km1 to generate pHJS304. In $\mathrm{pHJS} 304$ the insert is oriented in the opposite direction to the lac Z promoter such that expression of the napEDABC operon is controlled by its own promoter, together with $178 \mathrm{bp}$ of nap regulatory DNA. Plasmid pHJS304 was introduced into $P$. pantotrophus strain HJS105 by triparental mating. Exconjugants were selected on kanamycin plates.

Construction of pHJS308. The aim of this construction was to make a derivative of $\mathrm{pHJS} 304$, but which included the point mutation in the nap regulatory region. To do this plasmid oligonucleotides Hind $826 \mathrm{~N}$ and NapEpx were used to amplify a 263 bp DNA fragment from the promoter of the nap operon in mutant M6, which was cloned into pCR-Script to generate pHJS306. The HindIII-ClaI insert from pHJS306 was then cloned in a three-way ligation with the $4.2 \mathrm{~kb}$ ClaI-XhoI from pHJS4 and HindIII/Xhol-digested pBluescript II SK(+) to generate pHJS307. Finally, the insert from pHJS307 was isolated as a SacI fragment, which was cloned into SacIdigested pJB3Km1 to generate pHJS308. pHJS308 was then used to study nap operon expression in P. pantotrophus.

Construction of BCB12 (narl:: $\Omega$ ). Strain BCB12 was constructed by inserting the omega element (Prentki \& Kritsch, 1984) into the BamHI site of the narI gene. Transfer of the mutation to the $P$. pantotrophus chromosome was performed using the same methods as described for M6 $\Omega$ (Sears et al., 1997).

Sequence determination of $\boldsymbol{P}$. pantotrophus M6 promoter. Primers hsp86/hsp87 were used to amplify a 476 bp DNA fragment from $P$. pantotrophus M6 genomic DNA. The fragment was restricted with $S m a \mathrm{I} / \mathrm{BamHI}$ and ligated into SmaI/BamHI-restricted pUC18 to generate pHJS100M6. The sequence of the pHJS100M6 insert was determined using Universal and Reverse primers, as described below.

Enzyme assays. $\mathrm{MV}^{+}$was used to measure nitrate reductase enzyme activity. $\mathrm{MV}^{+}$-dependent nitrate reductase assays and chlorate reductase assays were performed exactly as described by Bell et al. (1990).

Automated DNA sequencing. Automated dye terminator sequencing was carried out using ABI Big Dye terminators and the reaction products were analysed on Applied Biosystems 377 automated sequencers. All sequence alignments, manipulations and analyses were performed using programs in the Wisconsin GCG software package version 10.0 for UNIX.

\section{RESULTS}

\section{Transcription of the napEDABC operon is regulated in response to the oxidation state of the carbon substrate}

It has previously been observed that the synthesis of NapA under aerobic growth conditions is dependent on the nature of the carbon substrate present in the growth medium (Richardson \& Ferguson, 1992; Table 2).
Primer extension analysis was used to determine where transcription initiated upstream of napE (Fig. 1a) and whether regulation in response to carbon source occurred at the level of transcription. Total RNA was isolated from cells grown aerobically and anaerobically with either succinate or butyrate as the sole carbon source. After the total RNA had been normalized, primer extension experiments were performed. Two relatively weak, but reproducible, initiation sites, termed P1 and P2, were identified (Fig. 2a, lane 2). The napE distal P1 start site was mapped to adjacent adenosine and guanosine nucleotides located 39 and $40 \mathrm{bp}$, respectively, upstream of the napE translation-initiation codon. The P1 site was observed weakly in aerobic succinate-grown cells. The napE proximal P2 site initiated at three adjacent nucleotides, the most upstream of which is located $31 \mathrm{bp}$ upstream of the napE translation-initiation codon (Figs $1 \mathrm{~b}$ and $2 \mathrm{a}$ ). The P2 transcript was predominant in cells grown aerobically with butyrate, and generally was estimated by densitometry to be between three- and fivefold more intense than the P1 transcript observed in cells grown aerobically on succinate. It should be noted that addition of nitrate to aerobically grown cells affected neither the intensity nor the pattern of the transcripts. Northern blotting experiments gave similar quantitative differences in transcript abundance to those noted with the transcript mapping (data not shown).

Analysis of total RNA from cells grown anaerobically with nitrate failed to detect the P2 transcript with butyrate as the carbon source (Fig. 2a); however, very minor amounts of P2 transcript were observed in anaerobic succinate-grown cells (Fig. 2a). A minor amount of the P1 transcript was observed in butyrategrown cells; however, the level of transcript was significantly reduced compared to the level of P2 transcript seen in aerobically grown cells. Taken together these findings indicate that transcription of the nap operon in $P$. pantotrophus initiates from two sites upstream of the napE gene, that expression is significantly reduced in anaerobic cells and that transcription is induced aerobically when butyrate is the carbon source.

Previous studies had shown that NAP enzyme activity was highest in cells grown aerobically with reduced carbon sources such as butyrate and was significantly lower in cells grown with more oxidized carbon sources such as malate or succinate (Richardson \& Ferguson, 1992). The results of the primer extension experiment described above suggest that the use of the P1 and P2 initiation sites is determined by the oxidation state of the carbon source. To test this hypothesis, total RNA was isolated from wild-type aerobic cells grown with malate, succinate, acetate or butyrate as the carbon source (Fig. $2 \mathrm{~b})$. The results indicate that the P1 site is indeed preferentially used when cells are grown on the oxidized carbon sources malate and succinate, whilst the more reduced substrate acetate results in $\mathrm{P} 1$ and $\mathrm{P} 2$ being used more or less equally. Cells grown on the most reduced substrate (butyrate) use P2 almost exclusively. 
Table 2. NAP activity is increased in the M6 mutant

Nitrate reductase activity was measured in periplasmic fractions and is expressed as $\mathrm{nmol} \mathrm{MV}^{+}$ oxidized (mg cell dry $\mathrm{wt})^{-1} \mathrm{~min}^{-1}$. The values in parentheses indicate the level of chlorate reductase enzyme activity and are also expressed as nmol $\mathrm{MV}^{+}$oxidized $(\mathrm{mg} \text { cell dry } \mathrm{wt})^{-1} \mathrm{~min}^{-1}$. Note that NAR catalyses the reduction of chlorate with a $V_{\max }$ approximately twice that of the value for nitrate (Craske \& Ferguson, 1986).

\begin{tabular}{|c|c|c|c|c|}
\hline \multirow[t]{2}{*}{ Growth conditions } & \multicolumn{4}{|c|}{$\mathrm{MV}^{+}$-dependent nitrate reduction } \\
\hline & Wild-type & $\begin{array}{c}\text { M6 } \\
(\mathrm{C} \rightarrow \mathrm{A})^{*}\end{array}$ & $\begin{array}{c}\text { pHJS304 } \\
(\text { WT },-178)^{*}\end{array}$ & $\begin{array}{c}\mathrm{pHJS308} \\
(\mathrm{C} \rightarrow \mathrm{A},-178)^{*}\end{array}$ \\
\hline Aerobic + succinate & $26(0)$ & $205(0)$ & $135(0)$ & $325(0)$ \\
\hline $\begin{array}{l}\text { Anaerobic + succinate } \\
+\mathrm{NO}_{3}\end{array}$ & $25(45)$ & $435(0)$ & $45(85)$ & $1530(66)$ \\
\hline Aerobic + butyrate & $1435(0)$ & $1620(0)$ & $4365(0)$ & $3505(0)$ \\
\hline $\begin{array}{l}\text { Anaerobic }+ \text { butyrate } \\
+\mathrm{NO}_{3}\end{array}$ & $25(45)$ & $500(0)$ & $22(27)$ & $2510(50)$ \\
\hline
\end{tabular}

* The genotype with respect to the nap regulatory region is presented in parenthesis. $\mathrm{C} \rightarrow \mathrm{A}$, indicates sequence transversion, WT indicates wild-type and -178 indicates the location of the $5^{\prime}$ deletion relative to the $\mathrm{P} 1$ transcription initiation site.

(a)

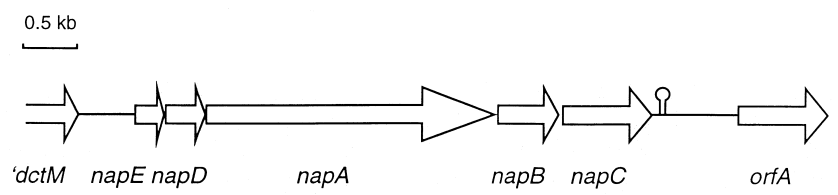

(b)

\section{ATGCGACCGCGCACGGATGGCTGGCCGGCCAGATGCCGCGCCG}

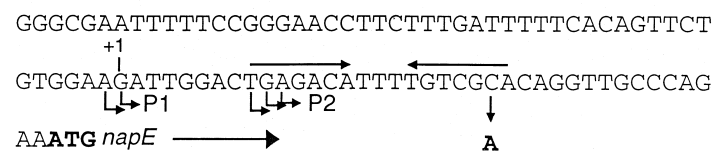

Fig. 1. Genetic organization of the nap operon of $P$. pantotrophus. (a) Schematic diagram indicating the organization of the nap genes. The hairpin structure at the $3^{\prime}$ end of the napC gene indicates a putative mRNA secondary structure. (b) DNA sequence immediately upstream of the napE gene (accession number Z36773). The ATG translation initiation codon of the napE gene is in bold and the direction of transcription of the nap operon is given by the large horizontal arrow. The more intense of the two bands of the P1 transcription start site is taken as +1 . The angled arrows indicate mapped $5^{\prime}$ ends of transcripts. The converging horizontal arrows above the sequence indicate a palindrome possibly involved in regulation of operon expression, and the location of the $C \rightarrow A$ transversion in mutant $M 6$ is indicated by the vertical arrow.

\section{$\mathrm{C} \rightarrow \mathrm{A}$ transversion in the nap regulatory region causes anaerobic derepression of nap operon transcription}

Under anaerobic growth conditions in wild-type cells, NAP enzyme activity is present at low levels (Table 2).
Strains of $P$. pantotrophus lacking the membraneassociated NAR enzyme are unable to grow anaerobically with nitrate (B. Berks \& D. Richardson, unpublished results), which indicates that under these conditions NAP activity is too low to support growth. In a previous study we isolated a $P$. pantotrophus narH::Tn5 insertion mutant, termed M6, that is deficient in NAR, yet after selection had regained the ability to grow anaerobically with nitrate (Bell et al., 1993). Thus, this mutant appeared to have become derepressed for the NAP enzyme, since nitrate reduction was supported under anaerobic conditions in the absence of a functional NAR. A more detailed analysis of NAP enzyme activity present in the periplasmic fraction of M6 cells grown aerobically or anaerobically with butyrate or succinate as carbon source is presented in Table 2. After aerobic growth in the presence of succinate, NAP activity was increased approximately $7 \cdot 5$-fold relative to the wild-type. Aerobic growth with butyrate as the carbon source resulted in a more than 50fold increase in NAP enzyme activity in the wild-type compared with the activity observed after growth with succinate. This result is in agreement with previous findings (Richardson \& Ferguson, 1992). Interestingly, NAP activity levels were similar in the wild-type and the mutant after aerobic growth in the presence of butyrate, which indicates that these values probably represent the maximum attainable NAP activity under these particular conditions. Anaerobic growth of the M6 mutant with either succinate or butyrate as the carbon source revealed a 17 - to 20 -fold increase in NAP activity relative to the values observed with the wild-type (Table 2).

Unlike the membrane-associated NAR enzyme, NAP does not accept chlorate as a substrate (Craske \& Ferguson, 1986). In wild-type cells grown anaerobically, a substantial chlorate reductase activity was detectable 

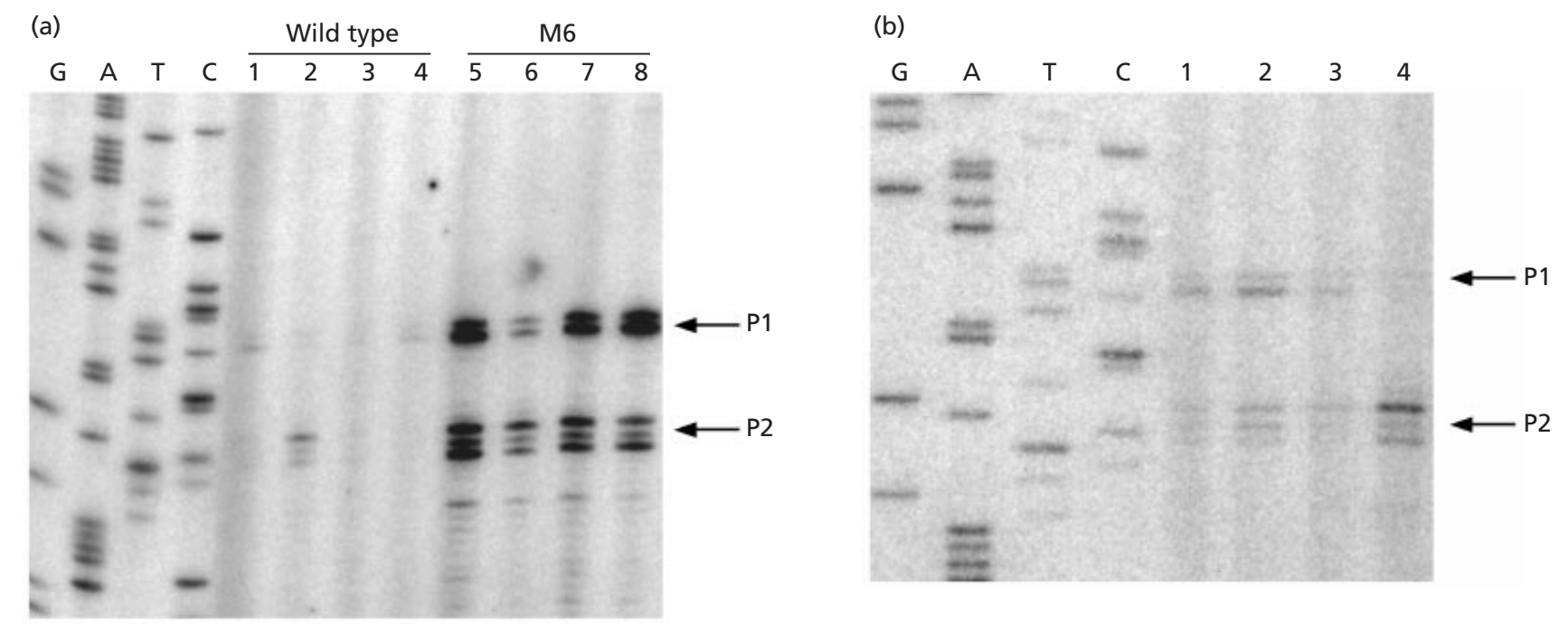

Fig. 2. Transcription analysis of the nap operon in the wild-type and the M6 mutant. (a) Equivalent aliquots of primer extension reactions (see Methods) were applied (with the exception of lane 6 , in which half the amount compared to the other lanes was applied) to a $6 \%$ denaturing polyacrylamide gel. Experiments were conducted with RNA isolated from the wild-type (lanes 1-4) and mutant M6 (lanes 5-8) strains. Lanes 1 and 5, RNA isolated from cells grown aerobically with succinate; lanes 2 and 6, RNA isolated from cells grown aerobically with butyrate; lanes 3 and 7, RNA isolated from cells grown anaerobically with succinate and nitrate; lanes 4 and 8, RNA isolated from cells grown anaerobically with butyrate and nitrate. The locations of the P1 and P2 transcripts are indicated. (b) Primer extension reactions of total RNA isolated from wild-type $P$. pantotrophus grown aerobically with different carbon sources were separated on a $6 \%$ denaturing polyacrylamide gel. Lane 1, cells grown on succinate; lane 2, grown on malate; lane 3, grown on acetate; lane 4, grown on butyrate. The oxidation state of the carbon sources decreases from the most oxidized malate through succinate, acetate and butyrate. The location of the P1 and P2 transcripts is indicated.

(Table 2), suggesting that the nitrate reductase observed may have been due in large part to NAR and not NAP. Significantly however, no chlorate reductase activity in the periplasmic fractions from anaerobically grown M6 cells was detected (Table 2), indicating that the nitrate reductase activity determined was exclusively due to NAP.

To investigate whether the substantial increase in NAP activity observed in the M6 mutant was a result of altered transcriptional regulation of the nap operon, mRNA prepared from M6 grown under aerobic and anaerobic conditions was analysed by primer extension (Fig. 2a). The results clearly demonstrate that nap operon transcription had become derepressed under all four growth conditions tested. The P1 and P2 transcripts were both present at roughly equal levels.

To ensure that the increase in nap expression was independent of the secondary nar mutation in M6, we constructed a different nar insertion mutant BCB12 (narI::S), which lacked the ability to grow anaerobically with either succinate and nitrate or butyrate and nitrate. This nar mutant also exhibited $\mathrm{MV}^{+}$-dependent NAP specific activities for aerobic succinate- and butyrate-grown cells, which were in a similar range to those observed for the wild-type. Furthermore, primer extension analysis of nap mRNA from this mutant showed a pattern of transcription indistinguishable from the wild-type (data not shown). Taken together, these data suggest that the M6 mutant carries a secondary mutation that lies outside the nar locus and which resulted in derepression of nap transcription.

All of the nap operon structural genes from the M6 mutant were sequenced and no mutation was found. However, sequence analysis of the $268 \mathrm{bp}$ of $5^{\prime}$ regulatory DNA immediately upstream of the napE translation initiation codon revealed a single $\mathrm{C} \rightarrow \mathrm{A}$ substitution (see Fig. 1b). The mutation lies 16 bases upstream from the napE translation start codon and 13 bp downstream from the P2 transcription start site. Amplification and sequencing of this DNA fragment was performed a number of times to exclude the possibility of the substitution having arisen through a PCR error.

To ensure that the $\mathrm{C} \rightarrow \mathrm{A}$ transversion was solely responsible for the derepression of nap operon transcription, two broad-host-range plasmids in which the complete napEDABC operon including $217 \mathrm{bp}$ of $5^{\prime}$ regulatory region were constructed (see Table 1 and Methods). Plasmid pHJS304 included the wild-type operon regulatory region, while $\mathrm{pHJS} 308$ included the $\mathrm{C} \rightarrow \mathrm{A}$ substitution. These plasmids were introduced into the nap deletion mutant HJS105 (Table 1). Direct analysis of $\mathrm{P} 1$ and $\mathrm{P} 2$ transcription by primer extension demonstrated that, as anticipated, the $\mathrm{C} \rightarrow \mathrm{A}$ transversion resulted in derepression of nap operon expression (Fig. 3), yielding a pattern similar to that seen with M6.

Comparative enzymic analysis of the periplasmic frac- 


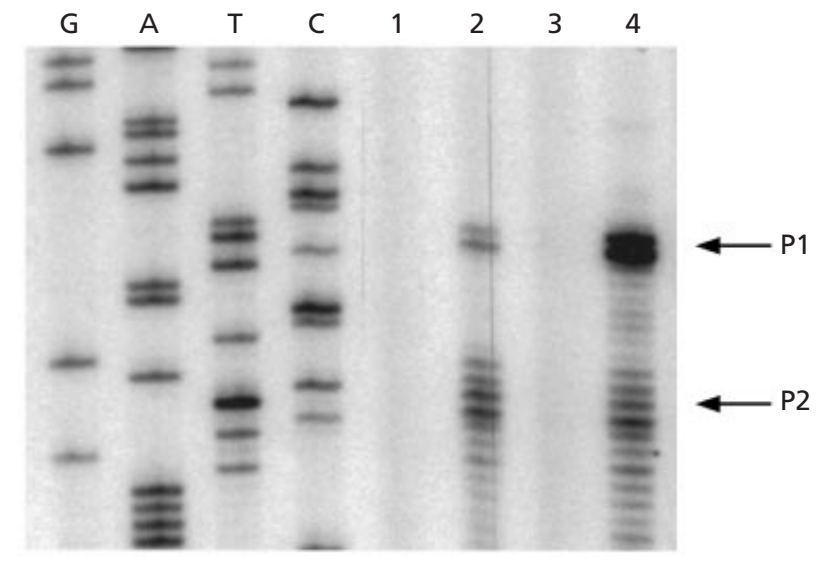

Fig. 3. Transcriptional regulation of nap operon expression in promoter deletion derivatives. Total RNA isolated from wildtype $P$. pantotrophus, mutant $\mathrm{M} 6$ and the $\triangle$ napEDABC mutant HJS105 containing pHJS304 or pHJS308 grown anaerobically on succinate and nitrate was analysed by primer extension and the products were separated on a $6 \%$ denaturing polyacrylamide gel. Lane 1, wild-type; lane 2, M6 mutant; lane 3, HJS105 $(\triangle$ napEDABC) containing pHJS304 (wild-type regulatory sequence); lane 4 HJS105 containing pHJS308 (regulatory sequence carrying the $\mathrm{C} \rightarrow \mathrm{A}$ transversion). The location of the P1 and P2 transcripts is indicated.

tion derived from these plasmid-bearing strains grown under a variety of conditions was undertaken (Table 2). The results revealed that the $\mathrm{C} \rightarrow \mathrm{A}$ mutation caused a 35 -fold increase in NAP activity relative to the wild-type regulatory region when the cells were grown anaerobically with succinate and nitrate. Notably, aerobic growth in the presence of succinate revealed only a $2 \cdot 5$ fold increase in activity in the mutant construct relative to the wild-type construct pHJS304. During aerobic growth with butyrate, NAP activity was high, with no major difference in the level of activity between the two constructs being observed (Table 2). These results indicate that the $\mathrm{C} \rightarrow \mathrm{A}$ transversion is responsible for the derepression of nap operon transcription. Moreover, that nap expression is independent of nar activity is confirmed by the finding that inactivation of the nap operon in M6 resulted in a strain lacking respiratory nitrate reductase enzyme activity under all conditions tested (Sears et al., 1997).

\section{DISCUSSION}

In an earlier study (Bell et al., 1993), it was noted that mutation of the narGHJI operon in M6 led to concomitant derepression of nap operon expression. At the time, this finding suggested overlapping transcriptional regulation of nar and nap operon expression. The results presented in this study now clearly demonstrate that the original M6 mutant had acquired a secondary mutation in the nap operon promoter region, which resulted in deregulation of the nap operon and consequent anaerobic growth of the M6 mutant on nitrate. Construction of a new nar mutant revealed that nap operon expression is independent of nar expression. Moreover, introduction of a single point mutation into the nap operon regulatory region in the absence of an additional nar operon mutation further confirmed that both operons are expressed independently of each other.

The transcriptional control of the $P$. pantotrophus nap operon features apparent dual regulation that combines control exerted by the nature of the carbon source and the requirement for aerobiosis. It is clear from the strong deregulation of nap transcription in the $P$. pantotrophus M6 mutant that at least part of this regulation involves a repression mechanism. The $\mathrm{C} \rightarrow \mathrm{A}$ point mutation in the nap operon regulatory region in M6 lies in a near perfect inverted heptamer repeat, TGaGACA- $\mathrm{N}_{3}$ TGTCgㄷA, which overlaps the lower of the two transcription start sites (Fig. 1b). This could be the recognition sequence for a repressor protein. The fact that transcription is also derepressed anaerobically suggests that this may be the binding site for an oxygendependent repressor. The obvious candidate for this would be an FNR-like protein; however, we were unable to identify a DNA sequence similar to the recognition sequence (TTGAT- $\mathrm{N}_{4}$-ATCAA) for FNR, which is common for FNR-like proteins from a number of microorganisms (Spiro, 1994; Sawers, 1999). Another possible candidate for an anaerobic repressor would be ArcA. Although ArcA has yet to be identified in a microorganism outside the enterobacteria, the regulation exhibited at the $P$. pantotrophus nap promoters is reminiscent of ArcA's mode of action at a number of E. coli promoters (Sawers, 1999).

It was notable that the nature of the carbon source had no apparent effect on transcription in the M6 mutant, whereas in the wild-type promoter it had a marked effect, with transcription increasing in the presence of butyrate. This may indicate either that the oxygendependent regulation overrides the carbon-source control or that both oxygen and carbon control may be mediated by the same repressor protein. The former is perhaps more likely, since it is difficult to reconcile how a single repressor protein could mediate both signals to which the nap operon promoters respond.

Transcription of the napEDABC operon initiates at two distinct sites, which are separated by 7 bp (Fig. 1). There are no obvious -10 and -35 promoter sequences showing similarity to those recognized by E. coli RNA polymerase; however, it should also be noted that RNA polymerase recognition sequences have yet to be defined in P. pantotrophus or its close relative Paracoccus denitrificans. The proximity of the start sites, coupled with the fact that they are used differentially depending on the carbon source, suggests that both are primary transcription start sites. Formally, this promoter arrangement is similar to that of the two promoters of the E. coli gal operon, which are separated by 5 bp (Choy \& Adhya, 1996). Expression of the gal promoters is controlled both positively and negatively by the GalR repressor. Depending on repressor concentration, GalR can repress one promoter and activate the other or 
repress transcription from both. Whether a similar control mechanism operates at the nap promoter must await further analysis.

In wild-type cells we determined that transcription from the P2 promoter was enhanced approximately fivefold during growth with butyrate as a substrate compared to the level of expression when the organism was grown with succinate. Clearly, however, this does not account for the greater than 50-fold increase in enzyme activity observed in the mutant under these conditions. Moreover, despite the high levels of transcript in the M6 mutant grown anaerobically with succinate and nitrate or with butyrate and nitrate, NAP enzyme activity did not attain the level observed in the M6 mutant grown aerobically with butyrate. This indicates that one or more of the processes of translation, cofactor insertion, or export limit NAP biosynthesis under these conditions, but not when the cells are grown aerobically with butyrate. This suggests that there is a further level of regulation controlling NAP enzyme synthesis, which is distinct from the transcriptional control.

During anaerobic growth of wild-type P. pantotrophus, NAP enzyme activity was reduced to the level observed when the cells were grown aerobically with oxidized carbon sources. This is a reflection of the fact that both promoters are essentially inactive during anaerobic growth. This is a logical bioenergetic rationale for the bacterium, as electron transport to nitrate via the FNRdependent NAR is more highly coupled than that via NAP and so it represents a more efficient means of energy conservation under anaerobic conditions. In contrast, during aerobic growth, because butyrate is more reduced than the average cell biomass of $P$. pantotrophus, the presence of NAP allows excess reductant to be readily dissipated during oxidative metabolism.

The molecular nature of the putative transcriptional repressor involved in nap regulation remains to be determined, but the work presented in this paper has provided the first insight into what is a new regulatory mechanism in bacteria that express nap aerobically and repress it anaerobically. Significantly, this regulatory mechanism must be distinct from that controlling nap expression in E. coli, and reflects the different physiological roles for NAP in these different bacterial species (Potter et al., 1999). Given that a number of other proteins appear to become up-regulated during aerobic growth on butyrate (H. J. Sears \& D. J. Richardson, unpublished observations) it is likely that this control system will have additional targets to the nap gene cluster. We now have the genetic and biochemical tools available to permit elucidation of this novel regulatory mechanism.

\section{ACKNOWLEDGEMENTS}

We are indebted to Ann Reilly for excellent technical assistance. This work was supported by BBSRC grant CO8666 to D. J.R., B. C.B. and S. J.F. and by the BBSRC via a grant-in- aid to the John Innes Centre to G.S. We are grateful to Rob van Spanning and Stephen Spiro for helpful discussions.

\section{REFERENCES}

Bedzyk, L., Wang, T. \& Ye, R. W. (1999). The periplasmic nitrate reductase in Pseudomonas sp. strain G-179 catalyses the first step of denitrification. J Bacteriol 181, 2802-2806.

Bell, L. C., Richardson, D. J. \& Ferguson, S. J. (1990). Periplasmic and membrane-bound respiratory nitrate reductases in Thiosphaera pantotropha: the periplasmic enzyme catalyses the first step in aerobic denitrification. FEBS Lett 265, 85-87.

Bell, L. C., Page, M. D., Berks, B. C., Richardson, D. J. \& Ferguson, S. J. (1993). Insertion of transposon Tn5 into a structural gene of the membrane-bound nitrate reductase of Thiosphaera pantotropha results in anaerobic overexpression of periplasmic nitrate reductase activity. J Gen Microbiol 139, 3205-3214.

Berks, B. C., Richardson, D. J., Reilly, A., Willis, A. C. \& Ferguson, S. J. (1995). The napEDABC cluster encoding the periplasmic nitrate reductase system of Thiosphaera pantotropha. Biochem J 309, 983-992.

Blatny, J. M., Brautaset, T., Winther-Larsen, H. C., Haugan, K. \& Valla, S. (1997). Construction and use of a versatile set of broadhost-range cloning and expression vectors based on the RK2 replicon. Appl Environ Microbiol 63, 370-379.

Choy, H. \& Adhya, S. (1996). Negative control. In Escherichia coli and Salmonella: Cellular and Molecular Biology, 2nd edn, pp. 1287-1299. Edited by F. C. Neidhardt and others. Washington, DC: American Society for Microbiology.

Craske, A. L. \& Ferguson, S. J. (1986). The respiratory nitrate reductase from Paracoccus denitrificans: molecular characterisation and kinetic properties. Eur J Biochem 158, 429-436.

Darwin, A. J. \& Stewart, V. (1995). Nitrate and nitrite regulation of the Fnr-dependent aeg-46.5 promoter of Escherichia coli K-12 is mediated by competition between homologous response regulators (NarL and NarP) for a common DNA-binding site. $J$ Mol Biol 251, 15-29.

Hanahan, D. (1983). Studies on transformation of Escherichia coli with plasmids. J Mol Biol 166, 557-563.

Figurski, D. H. \& Helinski, D. R. (1979). Replication of an origincontaining derivative of plasmid RK2 dependent on a plasmid function provided in trans. Proc Natl Acad Sci USA 76, 1648-1652.

Liu, H. P., Takio, S., Satoh, T. \& Yamamoto, I. (1999). Involvement in denitrification of the napKEFDABC genes encoding the periplasmic nitrate reductase system in the denitrifying phototrophic bacterium Rhodobacter sphaeroides f. sp. denitrificans. Biosci Biotechnol Biochem 63, 530-536.

Potter, L. C. \& Cole, J. A. (1999). Essential roles for the products of the nap $A B C D$ genes but not napFGH in periplasmic nitrate reduction by Escherichia coli K-12. Biochem J 344, 69-76.

Potter, L. C., Millington, P., Griffiths, L., Thomas, G. H. \& Cole, J. A. (1999). Competition between Escherichia coli strains expressing either a periplasmic or membrane-bound nitrate reductase: does NAP confer a selective advantage during nitratelimited growth? Biochem J 344, 77-84.

Prentki, P. \& Kritsch, H. M. (1984). In vitro insertional mutagenesis with a selectable DNA fragment. Gene 29, 303-313.

Richardson, D. J. \& Ferguson, S. J. (1992). The influence of the carbon substrate on the activity of the periplasmic nitrate reductase in aerobically grown Thiosphaera pantotropha. Arch Microbiol 157, 535-537. 
Robertson, L. A. \& Kuenen, J. G. (1983). Thiosphaera pantotropha gen. nov. sp. nov., a facultatively anaerobic, facultatively autotrophic sulphur bacterium. J Gen Microbiol 129, 2847-2855.

Sambrook, J., Fritsch, E. F. \& Maniatis, T. (1989). Molecular Cloning: a Laboratory Manual, 2nd edn. Cold Spring Harbor, NY: Cold Spring Harbor Laboratory.

Sanger, F., Nicklen, S. \& Coulson, A. R. (1977). DNA sequencing with chain-terminating inhibitors. Proc Natl Acad Sci US A 74, 5463-5467.

Sawers, G. (1999). The aerobic/anaerobic interface. Curr Opin Microbiol 2, 181-187.

Sawers, G. \& Böck, A. (1989). Novel transcriptional control of the pyruvate formate-lyase gene: upstream regulatory sequences and multiple promoters regulate anaerobic expression. J Bacteriol 171, 2485-2498.

Sears, H. J., Ferguson, S. J., Richardson, D. J. \& Spiro, S. (1993). The identification of a periplasmic nitrate reductase in Paracoccus denitrificans. FEMS Microbiol Lett 113, 107-112.

Sears, H. J., Little, P. J., Richardson, D. J., Berks, B. C., Spiro, S. \& Ferguson, S. J. (1997). Identification of an assimilatory nitrate reductase in mutants of Paracoccus denitrificans GB17 deficient in nitrate respiration. Arch Microbiol 167, 61-66.

Siddiqui, R. A., Warnecke-Eberz, U., Hengsberger, A., Schneider, B., Kostka, S. \& Friedrich, B. (1993). Structure and function of periplasmic nitrate reductase in Alcaligenes eutrophus H16. J Bacteriol 175, 5867-5876.
Spiro, S. (1994). The FNR family of transcriptional regulators. Antonie Leeuwenhoek 66, 23-36.

Van Spanning, R. J. M., Wansell, C. W., Harms, N., Oltmann, L. F. \& Stouthamer, A. H. (1990). Mutagenesis of the gene encoding cytochrome $c_{550}$ of Paracoccus denitrificans and analysis of the resultant physiological effects. J Bacteriol 172, 986-996.

Van Spanning, R. J. M., Wansell, C. W., Reijnders, W. N. M., Harms, N., Ras, J., Otmann, F. \& Stouthamer, A. H. (1991). A method for introduction of unmarked mutations in the genome of Paracoccus denitrificans: construction of strains with multiple mutations in the genes encoding periplasmic cytochromes $c_{550}$, $c_{551 \mathrm{i}}$, and $c_{553 \mathrm{i}} . J$ Bacteriol 173, 6962-6970.

Vieira, J. \& Messing, J. (1982). The pUC plasmids, an M13mp7derived system for insertion mutagenesis and sequencing with synthetic universal primers. Gene 19, 259-268.

Wang, H., Tseng, C. P. \& Gunsalus, R. P. (1999). The napF and nar $G$ nitrate reductase operons in Escherichia coli are differentially expressed in response to submicromolar concentrations of nitrate but not nitrite. J Bacteriol 181, 5303-5308.

Yanish-Perron, C., Vieira, J. \& Messing, J. (1985). Improved M13 cloning vectors and host strains: nucleotide sequences of the M13mp18 and pUC19 vectors. Gene 33, 103-119.

Received 6 April 2000; revised 24 July 2000; accepted 1 August 2000 